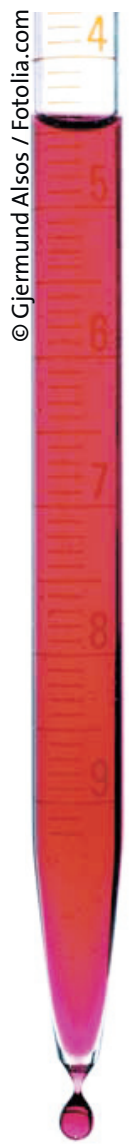

\section{Neues Adjuvans: Virus-Hüllproteine}

\begin{abstract}
Die spezifische Immuntherapie (SIT) ist wirksam, macht aber meist häufige Allergengaben notwendig und birgt die Gefahr von systemischen Reaktionen in sich. Ein völlig neues Ajuvans könnte möglicherweise diese Nachteile aufheben.
\end{abstract}

\begin{abstract}
chweizer Forscher haben eine neuartige Hyposensibilisierungsvakzine entwickelt, bei der repetitive 180 Untereinheiten eines $14-\mathrm{kD}-\mathrm{Hüll}-$ proteins des Bacteriophagen $\mathrm{Q} \beta$ verwendet werden. In diese Virus-ähnlichen Partikel wurde RNA von BakterienWirtszellen inkorporiert, die als Liganden für die Toll-likeRezeptoren (TLR) 3 und 7 fungieren. Die ausgeprägte TLR-Stimulation und die hochrepetitive Struktur des $\mathrm{Q} \beta$-Hüllproteins induzieren
\end{abstract}

\section{In den Laboren wird intensiv daran gearbeitet, die spezifi- sche Immuntherpie noch effek- tiver und sicherer zu machen.}

eine sehr ausgeprägte IgG-AntikörperAntwort.

Antigene, die an das $\mathrm{Q} \beta$-Hüllprotein gebunden werden, sind bei Mäusen und Menschen hoch immunogen. Wird beispielsweise das Katzenhauptallergen Fel d 1 an das Q $\beta$-Protein gebunden, entsteht eine hochwirksame SIT-Vakzine. Diese ist in der Lage, Fel-d-1-sensibilisierte Mäusen bereits nach einmaliger Injektion vor allergischen Reaktionen bei Allergenkonfrontation zu schützen.

Als entscheidende Effektorstrukturen für diesen rasch aufgebauten Immunschutz wurden die allergenspezifischen IgG-Antikörper identifiziert. Diese Antikörper inhibieren die allergenabhängige Mastzelldegranulation und heben somit die IgE-vermittelten Immunantworten bei Allergenexpositi- on auf. An den Injektionsstellen traten trotz der hohen Immunogenität von $\mathrm{Q} \beta$-Fel d 1 keine Lokalreaktionen auf, auch anaphylaktische Reaktionen nach massiver Allergenkonfrontation wurden nicht beobachtet. Außerdem wurde nach Zusatz von Q $\beta$-Feld 1 zu Basophilen, die aus dem Serum von Katzenallergikern isoliert worden waren, keine Degranulation beobachtet.

Fazit: An ein Virus-Hüllprotein gebundenes Katzenallergen führt bereits nach einmaliger Injektion bei sensibilisierten Mäusen zu einem guten Schutz vor allergischen Reaktionen. Trotz der hohen, überwiegend über IgG-Antikörper vermittelten Immunogenität der Virus-Allergen-Kombination traten im Tierversuch keine lokalen oder systemischen Effekte nach der Injektion auf. Eine Weiterentwicklung zu einer SIT-Vakzine ist denkbar.

\section{$b k$}

Schmitz $\mathbf{N}$ et al. Displaying Fel $\mathrm{d} 1$ on virus-like particles prevents reactogenicity despite greatly enhanced immunogenicity: a novel therapy for cat allergy. J Exp Med 2009; 206: 1941-55

\section{Heute eine Quaddel und morgen keine}

\section{Lässt sich aus einer Lokalreaktion bei der subkutanen spezifischen Immuntherapie (SCIT) eine weitere Lokalreaktion bei der nächsten Allergeninjektion vorhersagen? Dieser Frage gingen US-amerikanische Wissenschaftler in der LOCAL-Studie nach.}

\footnotetext{
$Z_{b}$ ur Untersuchung der Vorhersagbarkeit von Lokalreaktionen wurden retrospektiv Daten einer texanischen Klinik zur SCIT von 360 Patienten mit 9.678 Injektionen ausgewertet. An der Klinik war es nicht üblich, nach Auftreten einer Lokalreaktion die Allergendosis der nächsten Injektion zu verändern. Die SCIT umfasste ein bis zwei Injektionen pro Woche mit ansteigenden Allergenkonzentrationen über vier bis sechs Monate. 84\% der Patienten ließen sich gegen Aeroallergene hyposensibilisieren, 7\% gegen die Feuerameise, 3\% gegen fliegende Hymenopteren und $6 \%$ gegen eine Kombination dieser Allergene. In einer Daten-
}

bank wurde die Gesamtzahl der Injektionen pro Patient, kleine Lokalreaktionen (nicht größer als eine Handfläche des Patienten), ausgedehnte Lokalreaktionen (größer als die Handfläche), systemische Reaktionen und aufeinanderfolgende Lokalreaktionen erfasst.

$78,3 \%$ der Patienten entwickelten wenigstens einmal eine Lokalreaktion, 7,5\% eine ausgedehnte. Bei 16,3\% der Injektionen traten Lokalreaktionen auf, wobei mit $15,9 \%$ die meisten klein und nur $0,4 \%$ ausgedehnt waren.

Das Auftreten von Lokalreaktionen ließ keinerlei Rückschlüsse auf erneute Lokalreaktionen bei der nächsten SCITInjektion zu. Nur in 27,2\% der Fälle folgte einer Lokalreaktion eine weitere. Die Sensitivität für die Vorhersage betrug damit nur $26,2 \%$, der positive prädiktive Wert $27,2 \%$. Selbst auf ausgedehnte Lokalreaktionen folgte nur selten, nämlich in $6 \%$ der Fälle, eine weitere. Somit war auch hier kaum eine Prädiktion möglich, ob es wieder zu einer solchen Reaktion kommen könnte.

Fazit: Wird nach Lokalreaktionen bei der SCIT die Dosis bei der nächsten Allergeninjektion nicht angepasst, muss dennoch keine erneute Reaktion auftreten. Der prädiktive Wert einer einmal aufgetretenen Lokalreaktion - ob kleinflächig oder ausgedehnt - für eine weitere ist gering. Das unterstützt den Ansatz, die Dosis nach Auftreten von Lokalreaktionen nicht zu verändern. $f k$

Calabria CW et al. The Local Study: Local reactions do not predict local reactions in allergen immunotherapy. J Allergy Clin Immunol 2009; 124: 739-44 